\title{
Circadian Rhythm Disturbances in Patients with Alzheimer's Disease: A Review
}

\author{
Dawit A. Weldemichael and George T. Grossberg \\ Department of Neurology \& Psychiatry, Saint Louis University School of Medicine, St. Louis, MO 63104, USA \\ Correspondence should be addressed to Dawit A. Weldemichael, dweldemi@slu.edu \\ Received 21 April 2010; Accepted 27 July 2010 \\ Academic Editor: Ricardo Nitrini
}

Copyright ( 2010 D. A. Weldemichael and G. T. Grossberg. This is an open access article distributed under the Creative Commons Attribution License, which permits unrestricted use, distribution, and reproduction in any medium, provided the original work is properly cited.

\begin{abstract}
Circadian Rhythm Disturbances (CRDs) affect as many as a quarter of Alzheimer's disease (AD) patients during some stage of their illness. Alterations in the suprachiasmatic nucleus and melatonin secretion are the major factors linked with the cause of CRDs. As a result, the normal physiology of sleep, the biological clock, and core body temperature are affected. This paper systematically discusses some of the causative factors, typical symptoms, and treatment options for CRDs in patients with AD. This paper also emphasizes the implementation of behavioral and environmental therapies before embarking on medications to treat CRDs. Pharmacotherapeutic options are summarized to provide symptomatic benefits for the patient and relieve stress on their families and professional care providers. As of today, there are few studies relative to CRDs in AD. Large randomized trials are warranted to evaluate the effects of treatments such as bright light therapy and engaging activities in the reduction of CRDs in AD patients.
\end{abstract}

\section{Introduction}

Circadian rhythms are the regular; near 24 hs rest/wake patterns seen in normal individuals. There is a progressive deterioration of circadian rhythms with aging. These include changes in the sleep wake cycle manifested by reductions in sleep quality and impairment in cognitive performance $[1,2]$. Furthermore, exaggeration of age-related changes is seen in Alzheimer's Disease (AD) affecting as many as a quarter of patients during some stage of their illness. Few sleep questionnaires-based comparison studies have shown increased sleep disturbances in vascular cognitive disturbances compared to AD patients. CRDs also are noted to influence early recovery in poststroke patients [3].

Day-time agitation, night-time insomnia, and restlessness are among the common behavioral changes observed in AD. Nocturnal sleep disturbance is often accompanied by day-time napping, frequently in direct association with the extent of dementia [4].

Circadian Rhythm Disturbances (CRDs) in AD often present dramatically and are among the major triggers for institutionalization $[5,6]$. They are also associated with shorter survival in long-term care residents $[7,8]$ and are a cause of physical and psychological burden for caregivers [9].

\section{What does Cause CRDs?}

The main reason for the alteration in sleep-wake cycle is related to alterations in the suprachiasmatic nucleus (SCN) and melatonin secretion [10]. Though not clear, genetic risk factors such as in $\mathrm{AD}$ patients who are negative for the APOE- 4 allele have also been implicated in the development of sleep problems $[11,12]$.

The SCN of the anterior hypothalamus is the master clock controlling circadian rhythms in mammals. The SCN neurons exhibit near 24-hour electrical activity. The circadian influences of SCN neurons are distributed through different target organs by efferent neural and humoral signals particularly circulating melatonin. The nucleus controls melatonin secretion via a multisynaptic pathway producing changes in the biological clock, core body temperature, and sleep.

2.1. Biological Clock Changes. The activity of the SCN is regulated by environmental signals in a 24 -hour cycle and 
runs autonomously. It resets on a daily basis via light inputs from the retina during the day and melatonin secretion during the night. These inputs are conveyed through the retinohypothalamic tract (RHT) resulting in oscillation of SCN and melatonin secretion [13-15]. The RHT originates from the glutamatergic ganglion cells of the retina. These cells express pituitary adenylate cyclase-activating peptide (PACAP) which elicits phase shift signals in the SCN. There is also a serotonergic input from the midbrain raphe nuclei providing an arousal-dependent influence that can reset the circadian clock and modulate the photic synchronization of the SCN $[16,17]$.

The SCN contains gamma-aminobutyric acid (GABA) and arginine vasopressin (AVP) neurons that send a direct inhibitory projection to the nucleus of the paraventicular nucleus of the hypothalamus [18-20]. This in turn activates melatonin secretion by the pineal gland. Circulating melatonin acts via MT1 and MT2 receptors and inhibits the firing of the SCN. Hence, it promotes sleep and resets the circadian pacemaker. Melatonin secretion rises 2 hours before regular bedtime and remains elevated throughout the night.

As mentioned above, alterations in the SCN and melatonin secretion are assumed to be the main reason for CRD in AD [10]. Further, there is loss of expression of AVP and MT1 receptors in the SCN. These in turn result in a reduced production of melatonin and disappearance of normal melatonin rhythm $[21,22]$. The functional disruption of the $\mathrm{SCN}$ is even observed in the early stages of AD. The changes in the MT1 receptor explain why large studies have failed to show improvement in sleep-wake cycle after melatonin administration in $\mathrm{AD}$ patients [23].

2.2. Changes in Sleep Physiology. Certain sleep changes in AD seem to represent an exaggeration of changes that appear with normal aging. AD patients spend an increased amount of time in stage 1 sleep with increased number and duration of awakenings, compared to age-matched non-AD controls $[24,25]$.

With disease progression, it is also very difficult to separate EEG features of stage two sleep from stage 1 sleep. Sleep spindles and K complexes are poorly formed. They are also of lower amplitude, shorter duration, and much less numerous $[26,27]$. The proportion of nonrapid eye movement (NREM) sleep increases with further disappearance of the true delta wave of slow wave sleep (SWS) [24-28].

The percentage of time spent in REM sleep, which remains stable with normal aging, is reduced in patients with $\mathrm{AD}$ [26]. A decrease in the mean REM sleep episode duration and REM sleep percentage can be due to degeneration of the nucleus basalis of Meynert. The nucleus normally exerts an inhibitory influence on the nucleus reticularis of the thalamus, the rhythm generator responsible for NREM sleep [29].

REM sleep also depends on the abundance and integrity of the cholinergic system. The cholinergic disturbance in AD is accompanied by worsening of REM sleep. In addition, many subcortical structures such as the basal forebrain, distal and superior raphe nucleus, and the reticular formation of the pons and medulla seem to be involved in the initiation of sleep and oscillation between REM and non-REM states. All of these structures may potentially be damaged by the degenerative changes which are part of AD. Their deterioration may explain many of the sleep architecture and rhythm changes in $\mathrm{AD}$ (see Table 1).

2.3. Core Body Temperature Changes. In accordance with the endogenous circadian rhythm, melatonin also promotes sleep by lowering core body temperature via peripheral vascular dilatation [23]. Melatonin and core body temperature are inversely related. Lowest body temperature occurs 1-2 hours before awakening, generally between 4 and 5 AM. This corresponds to the maximum concentration of circulating melatonin levels. Core body temperature and melatonin are the two primary and measurable markers of the circadian cycle.

The core body temperature rhythm is generally accepted as yielding the best estimate of endogenous circadian amplitude and endogenous circadian phase in human subjects [30].

However, studies of circadian core body temperature rhythms in human subjects are complicated by the influence of many confounding variables (e.g., light, posture, meals, and social interaction) $[31,32]$. Keeping these different variables constant while measuring core body temperature, studies examining differences and similarities in circadian disturbances in groups of normal elderly and patients with probable $\mathrm{AD}$, as compared with a comparison group of young, normal volunteers have shown a reduction in endogenous circadian amplitude (ECA) and a delay in endogenous circadian phase (ECP) of core body temperature in patients with probable $\mathrm{AD}[33,34]$.

Studies have demonstrated that normal aging is accompanied by a $40 \%$ decrease in endogenous circadian amplitude. Related studies showing a 50\% reduction in amplitude in the $\mathrm{AD}$ group, as compared with normal young subjects could be interpreted as exaggerated or abnormal aging, rather than any discrete effect attributable to $\mathrm{AD}[30]$.

\section{Common AD Symptoms Related to CRDs}

Insomnia, nocturnal behavioral changes, and excessive daytime sleepiness, probably as a consequence of disrupted nocturnal sleep, are the common $\mathrm{AD}$ symptoms related to CRD. The actingout of REM sleep, often described as REM behavior disorder, is also briefly described here.

3.1. Insomnia. Insomnia in $\mathrm{AD}$ patients may have several etiologies. Though it may be primarily related to the underlying neurodegenerative changes producing CRD described above, other differential diagnostic issues need to be ruled out. For example, breathing problems during sleep, such as sleep apnea [35], with subsequent confusional arousal may be a possibility. A treatment trial with a continuous positive airway pressure (CPAP) breathing device has been reported to improve insomnia and even cognitive function in some patients. 
TABle 1: Changes in Sleep Parameters in AD.

Decrease in total sleep time
Decrease in efficiency of sleep with more fragmentation of sleep architecture
More time spent in stage 1 and stage 2 sleep and less time spent in deeper sleep
Increase in REM sleep latency and decreased REM sleep
Decreased density of eye movement activity

Insomnia may also be secondary to restless legs syndrome (RLS), where patients feel a need to pace in the evening or night-time hours. Several studies have shown that the severity of leg discomfort follows a circadian rhythm, reaching a peak after midnight. Most patients report difficulty falling asleep or waking up shortly after sleep onset with unpleasant leg sensations.

RLS, unlike the well-known mechanism of CRD, is mainly due to striatal dopamine depletion. Deficient iron transport and metabolism are also believed to result in RLS. If confirmed, serum ferritin levels may prove to be a useful laboratory marker [36].

Another common cause of insomnia especially in institutionalized or hospitalized AD patients may be secondary to noise in the environment and frequent room checks by staff. Bed checks are usually more frequent in incontinent patients to avoid decubitus ulcers.

Superimposed delirium can also interfere with restful night-time sleep. Simple measures such as treating urinary tract infections and pain, relieving fecal impaction, and reviewing the patient's current medications to determine if they may be promoting wakefulness or frequent awakenings [37] can result in drastic improvements of sleep and nocturnal agitation [38].

Macular degeneration and optic nerve degeneration are common conditions seen in AD which limit light input, further complicating circadian rhythms [39].

In patients with $\mathrm{AD}$, other psychiatric comorbidities, and in particular depression and anxiety, are also important causes of insomnia. Treatment of these psychopathologies may potentially ameliorate insomnia in AD patients.

Adding to sleep difficulties can be the excessive intake of stimulants such as coffee, tea, or caffeine containing soft drinks. Theophylline, commonly used for bronchopulmonary disease, is also a frequent cause of insomnia [40]. The cholinesterase inhibitors which are commonly prescribed in $\mathrm{AD}$, and in particular donepezil, have been shown to occasionally cause insomnia $[41,42]$.

3.2. Hypersomnia. Excessive daytime sleepiness (Hypersomnia) is related to changes either in NREM (Idiopathic hypersomnia), REM sleep (narcolepsy without cataplexy) or could be central in origin (narcolepsy with cataplexy). Narcolepsy is seldom described as a degenerative disease of the hypocreatin-containing neurons in the lateral hypothalamus. It may be accompanied by cataplexy or sudden loss of muscle tone, vivid hallucinations, and brief periods of total paralysis and REM sleep at inappropriate times. Patients experience sudden urge to sleep which usually lasts for few seconds or minutes. A mutation in chromosome 6 (controls the Human Leukocyte Antigen) is seen in $90 \%$ to $100 \%$ of patients. Narcolepsy is usually seen in early adulthood and it is very uncommon in elderly patients with AD [43].

In elderly, hypersomnia is more frequently seen in patients with Parkinson disease (PD), Lewy body dementia (DLB), or Parkinson disease dementia (PDD) than in AD. A recently discovered hypothalamic wake-stimulating neuropeptide, hypocretin-1, has been hypothesized to be involved in consolidation of wakefulness. Lower hypocretin1 levels may be permissive for increased wake fragmentation in $\mathrm{AD}$ resulting in daytime sleepiness. Stimulation of the hypocretin system may be a therapeutic means for improving daytime wakefulness in $\mathrm{AD}$ and in turn it helps sleep consolidation [44].

In $\mathrm{AD}$ patients, treatments of insomnia or medications used to control agitation at night are usually the most important causes of excessive daytime sleepiness (hypersomnia). In addition, the use of anticonvulsants and strongly anti cholinergic drugs such as antihistamines, antidiarrheals, and drugs used to reduce bladder irritability can cause daytime sedation and sleepiness [45].

Lack of engaging activities can also cause boredom and daytime sleepiness. At times, caregivers may promote daytime sleeping to ease their caregiving burden [46]. These in turn may result in night-time awakenings, further worsening the CRD [47-49].

3.3. Sundowning. Sundowning refers to agitation or a delirium-like state usually occurring late-afternoon/early evening or at night. Individual behavioral components of the condition which is frequently termed sundowning include loud vocalization, wandering, physical aggression, combativeness, maladaptive physical behaviors, and overall agitation [50-55]. These behaviors usually start at around 4 PM and last as late as 11 PM. However, some studies have reported the peak time of agitation as being in the afternoon, at approximately 2:30 PM, rather than in the early evening [56]. The prevalence of sundowning in $\mathrm{AD}$ ranges from $12 \%$ to $25 \%$ [57].

The tendency for agitation in $\mathrm{AD}$ to occur at night suggests that some changes in sleep and wakefulness in the $\mathrm{AD}$ patient (chronobiologic changes) may reflect alterations in the body's ability to regulate the timing of certain physiological events. Common factors which cause late day confusion or "sundowning" include exhaustion, reduced lighting, and increased shadows with inability to separate dream from reality when sleeping. Agitation usually worsens when patients are transferred to a new environment or a 
new nursing home or when there is a change or shifting of caregivers. "Sundowning" typically peaks in the middle stage of the disease and then diminishes as $\mathrm{AD}$ progresses [58].

3.4. REM Sleep Behavior Disorder. RBD is classified as either idiopathic or secondary to some identifiable causes. In most cases, it is due to neurodegenerative diseases. Narcoleptic patients may sometimes experience RBD due to degeneration of hypocreatin-containing hypothalamic neurons. It may also be induced by some medications (e.g., sedative hypnotics, tricyclic antidepressants, anticholinergics, selective serotonin reuptake inhibitors). Two case reports of Rivastagmine-(cholinesterase inhibitor-) induced RBD have been shown in AD patients [59].

REM sleep behavior disorder involves violent physical activity during dreaming. It is due to failure of the mechanism that produces atonia during REM sleep. There is a high level of tonic and phasic muscle activity seen most typically in REM sleep. This is suggested by electromyographic (EMG) activity recorded from facial and limb muscles during sleep. This condition can be seen in AD patients' comorbid with synucleiopathies such as Parkinsons disease and/or Diffuse Lewy Body dementia. Patients with REM sleep behavior disorder may sustain injuries to themselves or their bed partner. The disorder usually occurs in reaction to vivid dreams.

REM sleep behavior disorder should be distinguished from nocturnal paroxysmal dystonia (NPD) which is characterized by abnormal night-time movement of the trunk and head with alternating flexing and extension of the limbs. NPD is often considered to represent nocturnal frontal lobe epilepsy typically accompanied by abnormal slow wave and spike activity with paroxysmal intrusions in NREM, rather than REM sleep [61]. It is usually treated with anticonvulsants such as carbamazepine [62-64], unlike REM behavior Disorder which is usually treated with clonazepam [65].

\section{Treatment Approaches}

There is empirical evidence to support the use of behavioral and environmental strategies in alleviating sleep problems and night-time behavioral disturbances in patients with $\mathrm{AD}$. There are also certain pharmacological approaches to treat CRD-related symptoms. However, one needs to keep in mind that certain medications used for this purpose (e.g., benzodiazepines) can worsen cognitive deficits and obstructive sleep apnea syndrome (a condition commonly associated with $\mathrm{AD}$ ). In addition, some medications may also induce daytime sleepiness, resulting in night-time wakefulness.

4.1. Behavioral/Environmental Approaches. There are simple and effective interventions which should initially be tried to treat CRDs in $\mathrm{AD}$ patients. These include a regular activity schedule (e.g., serving dinner early), bed time routines, decreasing noise and night-time exposure to room level light, and limiting caffeine and alcohol intake [60]. Outpatients and long-term care residents with $\mathrm{AD}$ may spend too much time in bed and not enough time engaging in physical activities. This contributes to circadian rhythm abnormalities. Hence, physical activity may influence circadian rhythms. Mental, physical, and social activities to avoid boredom and daytime napping may be useful. Carvalho-Bos et al. used two-week actigraphic estimates of sleep-wake rhythm and investigated its association with a range of functional domains in 787 demented elderly women. They found that nocturnal restlessness is related to impairment in daily function and social interaction [66].

Typically, long-term care residents with $\mathrm{AD}$ are exposed to only a few minutes of bright light each day, even less than patients living in the community. Because light exposure is the strongest known "Zeitgeber" (time cue) in humans, lack of daytime light exposure may contribute to circadian dysregulation $[67,68]$. In one randomized controlled trial, 36 community-dwelling patients with $\mathrm{AD}$ were studied using a sleep survey and wrist actigraphy. Cases were randomized to daily exercise plus 60 minutes daily of bright light therapy (BLT) versus controls for 2 months. There was a significant reduction in the number of night-time awakenings, total time awake at night, and depression $(P<.05)$ in the treatment group. Patients were also followed for the next 6 months and benefits were maintained $[69,70]$.

In institutionalized patients, BLT has been shown to reduce daytime nap duration by 30 minutes during the treatment period $(P<.004)$ [70-72]. However, the effect in another study was not sustained after the cessation of light therapy [69, 73]. Another study has demonstrated modest benefits of bright light for two weeks on actigraphic measurements of activity [74-76]. A long-term (5 years) double blind, placebo-controlled randomized trial performed on 189 residents of 12 group care facilities in Netherlands has shown another modest benefit of bright light therapy in improving some of the cognitive and noncognitive symptoms of dementia. This effect is more attenuated when combined with melatonin administration $[77,78]$. In summary, regular exposure to bright light may be effective for day/night reversal problems [73, 79-81]. If the patient has RBD, removing potentially dangerous items from the bedroom and placing a soft mattress next to the bed may also help to ensure safety.

Clinical experience-based data also suggest that some $\mathrm{AD}$ patients with obstructive sleep apnea syndrome, treated with CPAP, may benefit from improved sleep consolidation [8284]. It is recommended that behavioral and environmental techniques should be tried first before resorting to pharmacologic approaches.

4.2. Pharmacological Approaches. There are various medications to treat insomnia, behavioral dyscontrol, and nocturnal agitation/wandering, excessive daytime sleepiness, REM sleep behavior disorder, and restless legs syndrome. Medications should always be combined with environmental/behavioral modifications. The choice of agent to use and dosing must be individualized. It is also the responsibility of the clinician to consider potential side effects and drug interactions. 
TABLE 2: Dosing schedule of medications used in CRD.

\begin{tabular}{|c|c|c|c|c|}
\hline Symptom & Medication & Initial Dose & Titrating Schedule & Maximum Daily Dose \\
\hline \multirow{5}{*}{ Insomnia } & Trazodone & $25 \mathrm{mg}$ hs & $25 \mathrm{mg}$ increments q $3-5$ days & $50-100 \mathrm{mg}$ \\
\hline & Zolpidem & $5 \mathrm{mg}$ hs & 5 mg increments q 3-4 days & $5-10 \mathrm{mg}$ \\
\hline & Mirtazapine & $15 \mathrm{mg}$ hs & 15 mg q week & $15-30 \mathrm{mg}$ \\
\hline & Quetiapine & $25 \mathrm{mg}$ hs & $25 \mathrm{mg}$ increments q 3-5 days & $25-100 \mathrm{mg}$ \\
\hline & Chloral hydrate & $250 \mathrm{mg}$ hs & $250 \mathrm{mg}$ increments q 5-7 days & $250-1000 \mathrm{mg}$ \\
\hline \multirow{9}{*}{ Behavioral Dyscontrol } & Memantine & $5 \mathrm{mg}$ am & $5 \mathrm{mg}$ increments q week & $20 \mathrm{mg}$ \\
\hline & Donepezil & $5 \mathrm{mg}$ am & $5 \mathrm{mg}$ increments in 4 weeks & $5-10 \mathrm{mg}$ \\
\hline & Rivastigmine Transdermal & $4.6 \mathrm{mg}$ od & $9.5 \mathrm{mg} 4$ weeks later & $9.5 \mathrm{mg}$ \\
\hline & Galantamine ER & $8 \mathrm{mg}$ od & $8 \mathrm{mg}$ increments q 4 weeks & $16-24 \mathrm{mg}$ \\
\hline & Risperidone & $0.25 \mathrm{mg}$ hs & $0.25 \mathrm{mg}$ increments q week & $0.5-1.5 \mathrm{mg}$ \\
\hline & Olanzapine & $2.5 \mathrm{mg}$ hs & $2.5 \mathrm{mg}$ increments q week & $5-10 \mathrm{mg}$ \\
\hline & Carbamazepine (check level) & $100 \mathrm{mg}$ hs & $100 \mathrm{mg}$ increments q 3-5 days bid or tid & $600 \mathrm{mg}$ \\
\hline & Oxcarbazepine & $300 \mathrm{mg}$ hs & $300 \mathrm{mg}$ increments q week & $2400 \mathrm{mg}$ \\
\hline & Divalproex ER (check level) & $125 \mathrm{mg}$ hs & $125 \mathrm{mg}$ increments q 3-4 days & $1500 \mathrm{mg}$ \\
\hline \multirow{2}{*}{ Excessive Daytime Sleepiness } & Methylphenidate & $2.5 \mathrm{mg}$ am & $2.5 \mathrm{mg}$ increments am and early pm & $20 \mathrm{mg}$ \\
\hline & Modafinil & $100 \mathrm{mg} \mathrm{am}$ & $100 \mathrm{mg}$ increments q week & $200 \mathrm{mg}$ \\
\hline \multirow{2}{*}{ REM Sleep Behavior Disorder } & Clonazepam & $0.25 \mathrm{mg}$ hs & $0.25 \mathrm{mg}$ increment $\mathrm{q}$ week & $1 \mathrm{mg}$ \\
\hline & Melatonin & $3 \mathrm{mg}$ hs & add $3 \mathrm{mg}$ if needed & $6 \mathrm{mg}$ \\
\hline
\end{tabular}

Adapted from Current management of sleep disturbances in dementia: [60].

Insomnia is a common problem which if left untreated/ undertreated may exacerbate the cognitive and non cognitive symptoms of $\mathrm{AD}$. Commonly used medications to promote sleep include trazodone, zolpidem, sedating antidepressants such as mirtazapine, less commonly, low doses of sedating atypical antipsychotics such as quetiapine, and chloral hydrate. (Refer to Table 2 for dosing). In considering the use of antipsychotics in the AD population, the FDA-issued warnings about increased risks of mortality, stroke, and stroke-like events need to be considered as part of risk/benefit calculations. As much as possible it is best to avoid benzodiazepines as they may worsen cognitive functions in $\mathrm{AD}$ patients. They can also impair balance and increase the risk of falls.

Nocturnal agitation/wandering, physical and verbal aggression, and hallucinations can also be treated pharmacologically after ruling out other medical and environmental causes and a trial of behavioral techniques. Atypical antipsychotics [85-87], anticonvulsants, short-acting benzodiazepines such as lorazepam or longer-acting agents (e.g., clonazepam), and trazodone may be effective measures. (Refer to Table 2 for dosing).

Cholinesterase inhibitors such as donepezil, rivastigmine, and galantamine may improve nocturnal behaviors over time [88, 89]. Cholinesterase inhibitors may significantly decrease evening-time hallucinations seen in $\mathrm{AD}$ patients [89]. Because of the dependence of REM sleep on the integrity of the cholinergic system, theoretically, one may predict increased REM sleep in cholinesterase inhibitor-treated AD patients [90]. Studies have found that rivastigmine increases the density of REM sleep in normal subjects [91]. However, cholinesterase inhibitors, especially donepezil, are also known to increase vivid dreams which subsequently may result in further disturbance in sleep $[92,93]$. A double-blind placebo-controlled trial done by Grossberg et al. has shown that $\mathrm{AD}$ patients who received memantine performed better on behavioral outcomes compared to placebo [94].

Clonazepam, started at a low dose of $0.25 \mathrm{mg}$ at night, is proven to be effective in the treatment of REM sleep behavior disorders [65]. Melatonin [95, 96] or pramipexole [97] can also be used in such cases although they are not as effective as clonazepam.

Although their use at higher doses is limited because of their potential for cardiovascular side effects in elderly, lower doses of methylphenidate or modafinil can be used if excessive daytime sleepiness is a problem. As usual, the risk/benefit ratio of these agents needs to be considered and discussed with patient/family before initiating these medications. It is also worth noting that stimulants may worsen some features of "sundowning ", for example, hallucinations.

Restless leg syndrome is a common condition which is not uncommonly seen in $\mathrm{AD}$ patients and which can further complicate CRD. Pramipexole $0.25 \mathrm{mg}$ p.o. hs or ropinirole $0.5 \mathrm{mg}$ p.o. hs are the commonly prescribed medications for this condition. The stimulating dopaminergic effect of these medicines can worsen sleep disturbance in some patients [65].

\section{Recommendations/Conclusions}

There are several causes of and contributors to CRD in AD. It is always important to rule out other potentially treatable comorbidities such as depression and delirium.

Caregiver understanding of the nature of $\mathrm{AD}$ and the implementation of environmental and behavioral techniques 
can reduce both patient and caregiver distress and may decrease hospital readmissions and delay institutionalization. We are beginning to understand the neuroanatomic, neurochemical, and endocrine underpinnings of CRDs in $\mathrm{AD}$ and their impact on sleep/wake disturbances as well as common behavioral abnormalities. At present, there is no definitive treatment to address the neurodegenerative changes underlying CRDs in $\mathrm{AD}$. However, current therapies, whether behavioral/environmental or pharmacotherapeutic, can provide symptomatic benefits for patients and relieve stress on their family or professional caregivers.

Large controlled studies are needed to evaluate the effects of treatments such as BLT and engaging daytime activities in the reduction of CRDs and resultant sleep/wake cycle and behavioral disturbances in $\mathrm{AD}$ patients.

\section{References}

[1] J. M. Oosterman, E. J. W. Van Someren, R. L. C. Vogels, B. Van Harten, and E. J. A. Scherder, "Fragmentation of the restactivity rhythm correlates with age-related cognitive deficits," Journal of Sleep Research, vol. 18, no. 1, pp. 129-135, 2009.

[2] J.-M. Yu, I.-J. Tseng, R.-Y. Yuan, J.-J. Sheu, H.-C. Liu, and C.-J. Hu, "Low sleep efficiency in patients with cognitive impairment," Acta Neurologica Taiwanica, vol. 18, no. 2, pp. 91-97, 2009.

[3] D. M. Hermann and C. L. Bassetti, "Sleep-related breathing and sleep-wake disturbances in ischemic stroke," Neurology, vol. 73, no. 16, pp. 1313-1322, 2009.

[4] P. R. Gehrman, M. Marler, J. L. Martin, et al., "The relationship between dementia severity and rest/activity circadian rhythms," Neuropsychiatric Disease and Treatment, vol. 1, no. 2, pp. 155-163, 2005.

[5] C. P. Pollak, D. Perlick, J. P. Linsner, J. Wenston, and F. Hsieh, "Sleep problems in the community elderly as predictors of death and nursing home placement," Journal of Community Health, vol. 15, no. 2, pp. 123-135, 1990.

[6] A. Bianchetti, A. Scuratti, O. Zanetti et al., "Predictors of mortality and institutionalization in Alzheimer disease patients 1 year after discharge from an Alzheimer dementia unit," Dementia, vol. 6, no. 2, pp. 108-112, 1995.

[7] P. Gehrman, M. Marler, J. L. Martin, T. Shochat, J. CoreyBloom, and S. Ancoli-Israel, "The timing of activity rhythms in patients with dementia is related to survival," Journals of Gerontology. Series A, vol. 59, no. 10, pp. 1050-1055, 2004.

[8] D. L. Bliwise, M. L. Hughes, J. S. Carroll, et al., "Mortality predicted by timing of temperature nadir in nursing home patients," Sleep Research, vol. 24, p. 510, 1995.

[9] S. M. McCurry, R. G. Logsdon, L. Teri, and M. V. Vitiello, "Sleep disturbances in caregivers of persons with dementia: contributing factors and treatment implications," Sleep Medicine Reviews, vol. 11, no. 2, pp. 143-153, 2007.

[10] D. F. Swaab, E. Fliers, and T. S. Partiman, "The suprachiasmatic nucleus of the human brain in relation to sex, age and senile dementia," Brain Research, vol. 342, no. 1, pp. 37-44, 1985.

[11] D. Craig, D. J. Hart, and A. P. Passmore, "Genetically increased risk of sleep disruption in Alzheimer's disease," Sleep, vol. 29, no. 8, pp. 1003-1007, 2006.

[12] J. A. Yesavage, L. Friedman, H. Kraemer et al., "Sleep/wake disruption in Alzheimer's disease: APOE status and longitudinal course," Journal of Geriatric Psychiatry and Neurology, vol. 17, no. 1, pp. 20-24, 2004.

[13] P. C. Zee and P. Manthena, "The brain's master circadian clock: implications and opportunities for therapy of sleep disorders," Sleep Medicine Reviews, vol. 11, no. 1, pp. 59-70, 2007.

[14] C. H. Ko and J. S. Takahashi, "Molecular components of the mammalian circadian clock," Human Molecular Genetics, vol. 15, no. 2, pp. R271-R277, 2006.

[15] E. Challet, "Minireview: entrainment of the suprachiasmatic clockwork in diurnal and nocturnal mammals," Endocrinology, vol. 148, no. 12, pp. 5648-5655, 2007.

[16] Y. Y. Lai, T. Shalita, T. Hajnik et al., "Neurotoxic N-methyl$\mathrm{D}$-aspartate lesion of the ventral midbrain and mesopontine junction alters sleep-wake organization," Neuroscience, vol. 90, no. 2, pp. 469-483, 1999.

[17] J. Arpa, C. Padrino, A. Rodríguez-Albariño, and I. De Andrés, "Centralis superior raphe, reticularis pontis nuclei, and sleepwakefulness cycle in cats," Journal of Sleep Research, vol. 7, no. 4, pp. 263-275, 1998.

[18] C. B. Saper, J. Lu, T. C. Chou, and J. Gooley, "The hypothalamic integrator for circadian rhythms," Trends in Neurosciences, vol. 28, no. 3, pp. 152-157, 2005.

[19] R. Y. Moore, J. C. Speh, and R. K. Leak, "Suprachiasmatic nucleus organization," Cell and Tissue Research, vol. 309, no. 1, pp. 89-98, 2002.

[20] S. J. Aton, C. S. Colwell, A. J. Harmar, J. Waschek, and E. D. Herzog, "Vasoactive intestinal polypeptide mediates circadian rhythmicity and synchrony in mammalian clock neurons," Nature Neuroscience, vol. 8, no. 4, pp. 476-483, 2005.

[21] K. Uchida, N. Okamoto, K. Ohara, and Y. Morita, "Daily rhythm of serum melatonin in patients with dementia of the degenerate type," Brain Research, vol. 717, no. 1-2, pp. 154159, 1996.

[22] D. Dori, G. Casale, S. B. Solerte et al., "Chrononeuroendocrinological aspects of physiological aging and senile dementia," Chronobiologia, vol. 21, no. 1-2, pp. 121-126, 1994.

[23] C. Singer, R. E. Tractenberg, J. Kaye et al., "A multicenter, placebo-controlled trial of melatonin for sleep disturbance in Alzheimer's disease," Sleep, vol. 26, no. 7, pp. 893-901, 2003.

[24] P. N. Prinz, P. P. Vitaliano, M. V. Vitiello, et al., "Sleep, EEG and mental function changes in senile dementia of the Alzheimer's type," Neurobiology of Aging, vol. 3, no. 4, pp. 361-370, 1982.

[25] C. F. Reynolds III, D. J. Kupfer, L. S. Taska, et al., "EEG sleep in elderly depressed, demented, and healthy subjects," Biological Psychiatry, vol. 20, no. 4, pp. 431-442, 1985.

[26] J. Montplaisir, D. Petit, D. Lorrain, S. Gauthier, and T. Nielsen, "Sleep in Alzheimer's disease: further considerations on the role of brainstem and forebrain cholinergic populations in sleep-wake mechanisms," Sleep, vol. 18, no. 3, pp. 145-148, 1995.

[27] P. N. Prinz, E. R. Peskind, P. P. Vitaliano, et al., "Changes in the sleep and waking EEGs of nondemented and demented elderly subjects," Journal of the American Geriatrics Society, vol. 30, no. 2, pp. 86-93, 1982.

[28] C. F. Reynolds III, D. J. Kupfer, and L. S. Taska, "EEG sleep in elderly depressed, demented, and healthy subjects," Biological Psychiatry, vol. 20, no. 4, pp. 431-442, 1985.

[29] G. Buzsaki, R. G. Bickford, G. Ponomareff, L. J. Thal, R. Mandel, and F. H. Gage, "Nucleus basalis and thalamic control of neocortical activity in the freely moving rat," Journal of Neuroscience, vol. 8, no. 11, pp. 4007-4026, 1988. 
[30] C. A. Czeisler, M. Dumont, J. F. Duffy et al., "Association of sleep-wake habits in older people with changes in output of circadian pacemaker," Lancet, vol. 340, no. 8825, pp. 933-936, 1992.

[31] J. Aschoff, "Exogenous and endogenous components in circadian rhythms," Cold Spring Harbor Symposia on Quantitative Biology, vol. 25, pp. 11-28, 1960.

[32] J. N. Mills, D. S. Minors, and J. M. Waterhouse, "The effect of sleep upon human circadian rhythms," Chronobiologia, vol. 5, no. 1, pp. 14-27, 1978.

[33] S. Ancoli-Israel, M. R. Klauber, D. W. Jones et al., "Variations in circadian rhythms of activity, sleep, and light exposure related to dementia in nursing-home patients," Sleep, vol. 20, no. 1, pp. 18-23, 1997.

[34] A. Satlin, L. Volicer, E. G. Stopa, and D. Harper, "Circadian locomotor activity and core-body temperature rhythms in Alzheimer's disease," Neurobiology of Aging, vol. 16, no. 5, pp. 765-771, 1995.

[35] D. L. Bliwise, “Sleep apnea, APOE4 and Alzheimer's disease 20 years and counting?" Journal of Psychosomatic Research, vol. 53, no. 1, pp. 539-546, 2002.

[36] S. T. O'Keeffe, K. Gavin, and J. N. Lavan, "Iron status and restless legs syndrome in the elderly," Age and Ageing, vol. 23, no. 3, pp. 200-203, 1994.

[37] T. Shochat, J. Loredo, and S. Ancoli-Israel, "Sleep disorders in elderly," Current Treatment Options in Neurology, vol. 3, pp. 19-36, 2001.

[38] S. K. Inouye, S. T. Bogardus Jr., P. A. Charpentier et al., "A multicomponent intervention to prevent delirium in hospitalized older patients," New England Journal of Medicine, vol. 340, no. 9, pp. 669-676, 1999.

[39] D. R. Hinton, A. A. Sadun, J. C. Blanks, and C. A. Miller, "Optic-nerve degeneration in Alzheimer's disease," New England Journal of Medicine, vol. 315, no. 8, pp. 485-487, 1986.

[40] W. C. Bailey, J. M. Richards Jr., B. A. Manzella, M. Brooks, R. A. Windsor, and S.-J. Soong, "Characteristics and correlates of asthma in a university clinic population," Chest, vol. 98, no. 4, pp. 821-828, 1990.

[41] S. L. Rogers, R. S. Doody, R. C. Mohs, and L. T. Friedhoff, "Donepezil improves cognition and global function in Alzheimer disease: a 15-week, double-blind, placebocontrolled study," Archives of Internal Medicine, vol. 158, no. 9, pp. 1021-1031, 1998.

[42] A. Burns, M. Rossor, J. Hecker et al., "The effects of donepezil in Alzheimer's disease-results from a multinational trial," Dementia and Geriatric Cognitive Disorders, vol. 10, no. 3, pp. 237-244, 1999.

[43] R. J. Wurtman, "Narcolepsy and the hypocretins," Metabolism, vol. 55, no. 2, pp. S36-S39, 2006.

[44] L. F. Friedman, J. M. Zeitzer, L. Lin et al., "In Alzheimer disease, increased wake fragmentation found in those with lower hypocretin-1," Neurology, vol. 68, no. 10, pp. 793-794, 2007.

[45] National Sleep Foundation, Sleep in America Poll, WB and A Market Research, Washington, DC, USA, 2003.

[46] S. M. McCurry, R. G. Logsdon, L. Teri et al., "Characteristics of sleep disturbance in community-dwelling Alzheimer's disease patients," Journal of Geriatric Psychiatry and Neurology, vol. 12, no. 2, pp. 53-59, 1999.

[47] K. Meguro, M. Ueda, I. Kobayashi et al., "Sleep disturbance in elderly patients with cognitive impairment, decreased daily activity and periventricular white matter lesions," Sleep, vol. 18, no. 2, pp. 109-114, 1995.
[48] D. L. Bliwise, J. S. Carroll, and W. C. Dement, "Predictors of observed sleep/wakefulness in residents in long-term care," Journals of Gerontology, vol. 45, no. 4, pp. M126-M130, 1990.

[49] S. R. Allen, W. O. Seiler, H. B. Stahelin, and R. Spiegel, "Seventy-two hour polygraphic and behavioral recordings of wakefulness and sleep in a hospital geriatric unit: comparison between demented and nondemented patients," Sleep, vol. 10, no. 2, pp. 143-159, 1987.

[50] D. L. Algase, "Wandering in dementia," Annual Review of Nursing Research, vol. 17, pp. 185-217, 1999.

[51] D. L. Bliwise, "What is sundowning?" Journal of the American Geriatrics Society, vol. 42, no. 9, pp. 1009-1011, 1994.

[52] D. L. Bliwise, "Sleep in normal aging and dementia," Sleep, vol. 16, no. 1, pp. 40-81, 1993.

[53] D. Martino-Saltzman, B. B. Blasch, R. D. Morris, and L. W. McNeal, "Travel behavior of nursing home residents perceived as wanderers and nonwanderers," Gerontologist, vol. 31, no. 5, pp. 666-672, 1991.

[54] L. D. Burgio, K. Scilley, J. M. Hardin et al., "Studying disruptive vocalization and contextual factors in the nursing home using computer-assisted real-time observation," Journals of Gerontology, vol. 49, no. 5, pp. P230-P239, 1994.

[55] P. A. O'Leary, W. E. Haley, and P. B. Paul, "Behavioral assessment in Alzheimer's disease: use of a 24-hr log," Psychology and Aging, vol. 8, no. 2, pp. 139-143, 1993.

[56] J. Martin, M. Marler, T. Shochat, and S. Ancoli-Israel, "Circadian rhythms of agitation in institutionalized patients with Alzheimer's disease," Chronobiology International, vol. 17, no. 3, pp. 405-418, 2000.

[57] M. H. Kryger, T. Roth, and W. C. Dement, Principles and Practice of Sleep Medicine, W. B. Saunders, Philadelphia, Pa, USA, 3rd edition, 2000.

[58] F. W. Myron and M. L. Anne, Textbook of Alzheimer's Disease and Other Dementias, vol. 8, American Psychiatric , 2009.

[59] S.-B. Yeh, P.-Y. Yeh, and C. H. Schenck, "Rivastigmine-induced REM sleep behavior disorder (RBD) in a 88-year-old man with Alzheimer's disease," Journal of Clinical Sleep Medicine, vol. 6, no. 2, pp. 192-195, 2010.

[60] J. G. Ouslander, B. R. Connell, D. L. Bliwise, Y. Endeshaw, P. Griffiths, and J. F. Schnelle, "A nonpharmacological intervention to improve sleep in nursing home patients: results of a controlled clinical trial," Journal of the American Geriatrics Society, vol. 54, no. 1, pp. 38-47, 2006.

[61] F. Provini, G. Plazzi, P. Tinuper, S. Vandi, E. Lugaresi, and P. Montagna, "Nocturnal frontal lobe epilepsy: a clinical and polygraphic overview of 100 consecutive cases," Brain, vol. 122, no. 6, pp. 1017-1031, 1999.

[62] S.-B. Yeh, P.-Y. Yeh, and C. H. Schenck, "Rivastigmine-induced REM sleep behavior disorder (RBD) in a 88-year-old man with Alzheimer's disease," Journal of Clinical Sleep Medicine, vol. 6, no. 2, pp. 192-195, 2010.

[63] C. Marini and R. Guerrini, "The role of the nicotinic acetylcholine receptors in sleep-related epilepsy," Biochemical Pharmacology, vol. 74, no. 8, pp. 1308-1314, 2007.

[64] F. Provini, G. Plazzi, P. Montagna, and E. Lugaresi, "The wide clinical spectrum of nocturnal frontal lobe epilepsy," Sleep Medicine Reviews, vol. 4, no. 4, pp. 375-386, 2000.

[65] B. F. Boeve, M. H. Silber, and T. J. Ferman, "Current management of sleep disturbances in dementia," Current Neurology and Neuroscience Reports, vol. 2, no. 2, pp. 169-177, 2002.

[66] S. S. Carvalho-Bos, R. F. Riemersma-van Der Lek, J. Waterhouse, T. Reilly, and E. J. W. Van Someren, "Strong association 
of the rest-activity rhythm with well-being in demented elderly women," American Journal of Geriatric Psychiatry, vol. 15, no. 2, pp. 92-100, 2007.

[67] S. S. Campbell, D. F. Kripke, J. C. Gillin, and J. C. Hrubovcak, "Exposure to light in healthy elderly subjects and Alzheimer's patients," Physiology and Behavior, vol. 42, no. 2, pp. 141-144, 1988.

[68] S. Ancoli-Israel, J. L. Martin, D. F. Kripke, M. Marler, and M. R. Klauber, "Effect of light treatment on sleep and circadian rhythms in demented nursing home patients," Journal of the American Geriatrics Society, vol. 50, no. 2, pp. 282-289, 2002.

[69] S. M. McCurry, L. E. Gibbons, R. G. Logsdon, M. V. Vitiello, and L. Teri, "Nighttime insomnia treatment and education for Alzheimer's disease: a randomized, controlled trial," Journal of the American Geriatrics Society, vol. 53, no. 5, pp. 793-802, 2005.

[70] J. K. Gammack, "Light therapy for insomnia in older adults," Clinics in Geriatric Medicine, vol. 24, no. 1, pp. 139-149, 2008.

[71] A. Fetveit and B. Bjorvatn, "Bright-light treatment reduces actigraphic-measured daytime sleep in nursing home patients with dementia: a pilot study," American Journal of Geriatric Psychiatry, vol. 13, no. 5, pp. 420-423, 2005.

[72] J. G. Ouslander, B. R. Connell, D. L. Bliwise, Y. Endeshaw, P. Griffiths, and J. F. Schnelle, "A nonpharmacological intervention to improve sleep in nursing home patients: results of a controlled clinical trial," Journal of the American Geriatrics Society, vol. 54, no. 1, pp. 38-47, 2006.

[73] K. Mishima, M. Okawa, Y. Hishikawa, S. Hozumi, H. Hori, and K. Takahashi, "Morning bright light therapy for sleep and behavior disorders in elderly patients with dementia," Acta Psychiatrica Scandinavica, vol. 89, no. 1, pp. 1-7, 1994.

[74] S. Ancoli-Israel, P. Gehrman, J. L. Martin et al., "Increased light exposure consolidates sleep and strengthens circadian rhythms in severe Alzheimer's disease patients," Behavioral Sleep Medicine, vol. 1, no. 1, pp. 22-36, 2003.

[75] S. Ancoli-Israel, J. L. Martin, P. Gehrman et al., "Effect of light on agitation in institutionalized patients with severe Alzheimer disease," American Journal of Geriatric Psychiatry, vol. 11, no. 2, pp. 194-203, 2003.

[76] S. Ancoli-Israel, D. W. Jones, M. A. Hanger, et al., "Sleep in the nursing home," in Sleep and Respiration in Aging Adults, pp. 77-84, Elsevier, New York, NY, USA, 1991.

[77] R. F. Riemersma-van Der Lek, D. F. Swaab, J. Twisk, E. M. Hol, W. J. G. Hoogendijk, and E. J. W. Van Someren, "Effect of bright light and melatonin on cognitive and noncognitive function in elderly residents of group care facilities: a randomized controlled trial," Journal of the American Medical Association, vol. 299, no. 22, pp. 2642-2655, 2008.

[78] K. Asayama, H. Yamadera, T. Ito, H. Suzuki, Y. Kudo, and S. Endo, "Double blind study of melatonin effects on the sleep-wake rhythm, cognitive and non-cognitive functions in Alzheimer type dementia," Journal of Nippon Medical School, vol. 70, no. 4, pp. 334-341, 2003.

[79] C. G. Lyketsos, L. L. Veiel, A. Baker, and C. Steele, "A randomized, controlled trial of bright light therapy for agitated behaviors in dementia patients residing in long-term care," International Journal of Geriatric Psychiatry, vol. 14, no. 7, pp. 520-525, 1999.

[80] E. J. W. Van Someren, A. Kessler, M. Mirmiran, and D. F. Swaab, "Indirect bright light improves circadian restactivity rhythm disturbances in demented patients," Biological Psychiatry, vol. 41, no. 9, pp. 955-963, 1997.

[81] A. Fetveit and B. Bjorvatn, "Bright-light treatment reduces actigraphic-measured daytime sleep in nursing home patients with dementia: a pilot study," American Journal of Geriatric Psychiatry, vol. 13, no. 5, pp. 420-423, 2005.

[82] B. Naegele, J.-L. Pepin, P. Levy, C. Bonnet, J. Pellat, and C. Feuerstein, "Cognitive executive dysfunction in patients with obstructive sleep apnea syndrome (OSAS) after CPAP treatment," Sleep, vol. 21, no. 4, pp. 392-397, 1998.

[83] H. M. Engleman, S. E. Martin, I. J. Deary, and N. J. Douglas, "Effect of continuous positive airway pressure treatment on daytime function in sleep apnoea/hypopnoea syndrome," Lancet, vol. 343, no. 8897, pp. 572-575, 1994.

[84] M. Valencia-Flores, D. L. Bliwise, C. Guilleminault, R. Cilveti, and A. Clerk, "Cognitive function in patients with sleep apnea after acute nocturnal nasal continuous positive airway pressure (CPAP) treatment: sleepiness and hypoxemia effects," Journal of Clinical and Experimental Neuropsychology, vol. 18, no. 2, pp. 197-210, 1996.

[85] J. S. Street, W. S. Clark, K. S. Gannon et al., "Olanzapine treatment of psychotic and behavioral symptoms in patients with Alzheimer disease in nursing care facilities: a doubleblind, randomized, placebo-controlled trial," Archives of General Psychiatry, vol. 57, no. 10, pp. 968-976, 2000.

[86] D. Q. McManus, L. A. Arvanitis, and B. B. Kowalcyk, "Quetiapine, a novel antipsychotic: experience in elderly patients with psychotic disorders," Journal of Clinical Psychiatry, vol. 60, no. 5, pp. 292-298, 1999.

[87] I. R. Katz, D. V. Jeste, J. E. Mintzer, C. Clyde, J. Napolitano, and M. Brecher, "Comparison of risperidone and placebo for psychosis and behavioral disturbances associated with dementia: a randomized, double-blind trial," Journal of Clinical Psychiatry, vol. 60, no. 2, pp. 107-115, 1999.

[88] S. M. Stahl, J. S. Markowitz, E. M. Gutterman, and G. Papadopoulos, "Co-use of donepezil and hypnotics among Alzheimer's disease patients living in the community," Journal of Clinical Psychiatry, vol. 64, no. 4, pp. 466-472, 2003.

[89] L. E. Maclean, C. C. Collins, and E. J. Byrne, "Dementia with Lewy bodies treated with rivastigmine: effects on cognition, neuropsychiatric symptoms, and sleep," International Psychogeriatrics, vol. 13, no. 3, pp. 277-288, 2001.

[90] M. Schredl, B. Weber, M.-L. Leins, and I. Heuser, "Donepezilinduced REM sleep augmentation enhances memory performance in elderly, healthy persons," Experimental Gerontology, vol. 36, no. 2, pp. 353-361, 2001.

[91] E. Holsboer-Trachsler, M. Hatzinger, R. Stohler et al., "Effects of the novel acetylcholinesterase inhibitor SDZ ENA 713 on sleep in man," Neuropsychopharmacology, vol. 8, no. 1, pp. 8792, 1993.

[92] G. A. Yorston and R. Gray, "Hypnopompic hallucinations with donepezil," Journal of Psychopharmacology, vol. 14, no. 3, pp. 303-304, 2000.

[93] J. S. Ross and J. R. Shua-Haim, "Aricept-induced nightmares in Alzheimer's disease: 2 case reports," Journal of the American Geriatrics Society, vol. 46, no. 1, pp. 119-120, 1998.

[94] G. T. Grossberg, V. Pejović, M. L. Miller, and S. M. Graham, "Memantine therapy of behavioral symptoms in communitydwelling patients with moderate to severe Alzheimer's disease," Dementia and Geriatric Cognitive Disorders, vol. 27, no. 2, pp. 164-172, 2009.

[95] D. Kunz and F. Bes, "Melatonin as a therapy in REM sleep behavior disorder patients: an open-labeled pilot study on the possible influence of melatonin on REM-sleep regulation," Movement Disorders, vol. 14, no. 3, pp. 507-511, 1999. 
[96] B. F. Boeve, M. H. Silber, and T. J. Ferman, "Melatonin for treatment of REM sleep behavior disorder in neurologic disorders: results in 14 patients," Sleep Medicine, vol. 4, no. 4, pp. 281-284, 2003.

[97] M. L. Fantini, J.-F. Gagnon, D. Filipini, and J. Montplaisir, "The effects of pramipexole in REM sleep behavior disorder," Neurology, vol. 61, no. 10, pp. 1418-1420, 2003. 


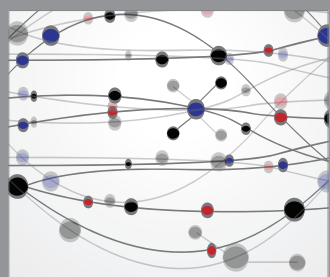

The Scientific World Journal
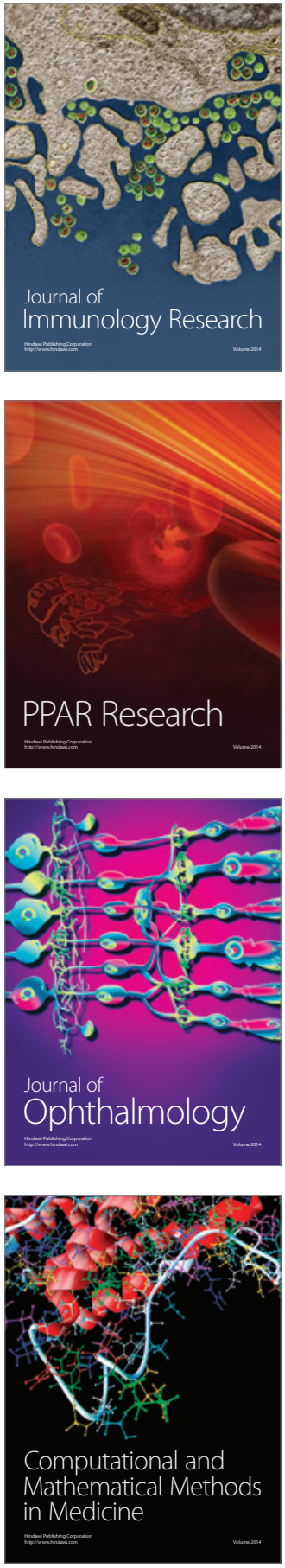

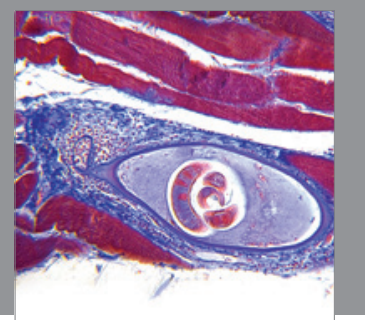

Gastroenterology

Research and Practice
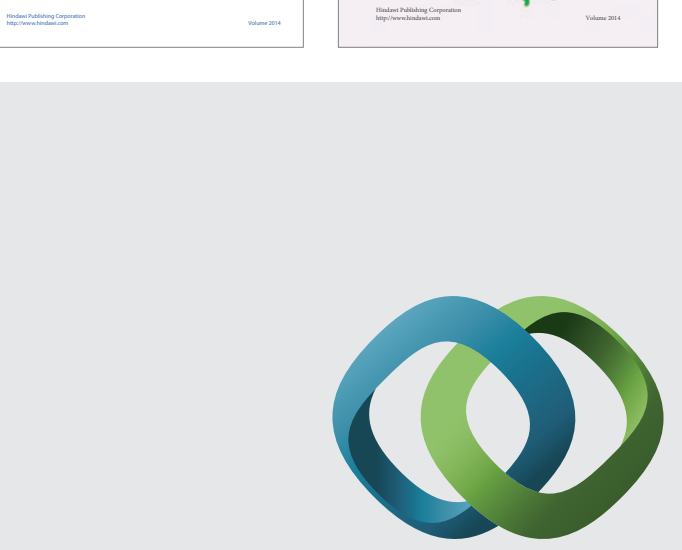

\section{Hindawi}

Submit your manuscripts at

http://www.hindawi.com
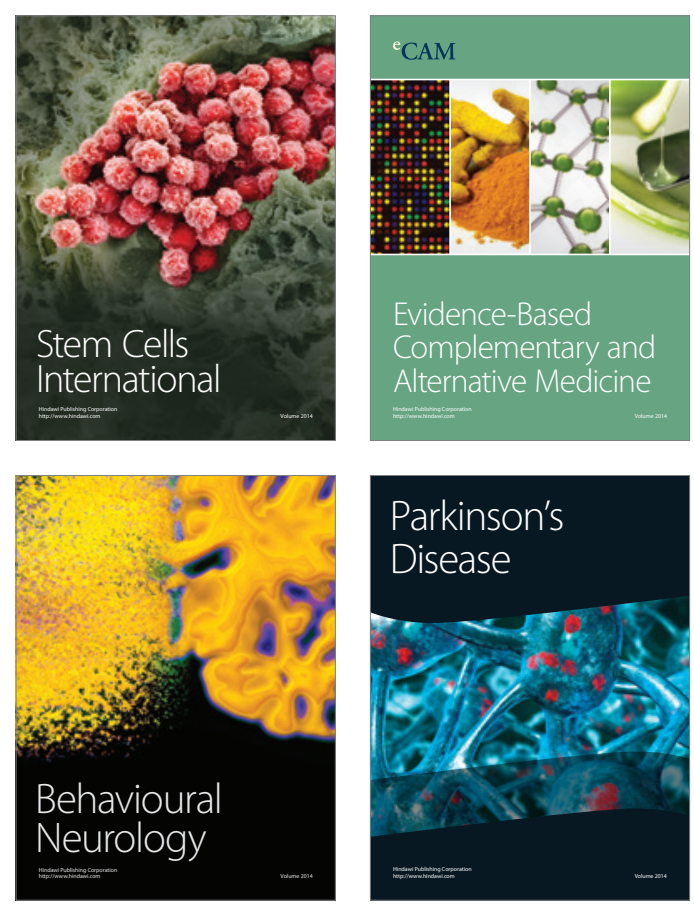

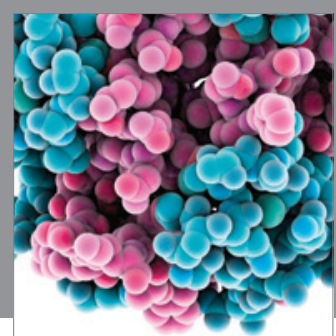

Journal of
Diabetes Research

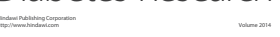

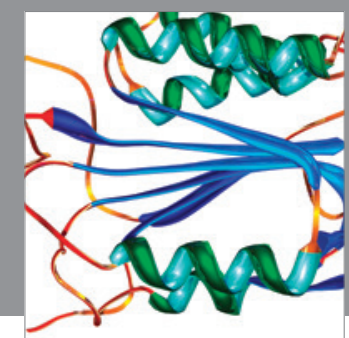

Disease Markers
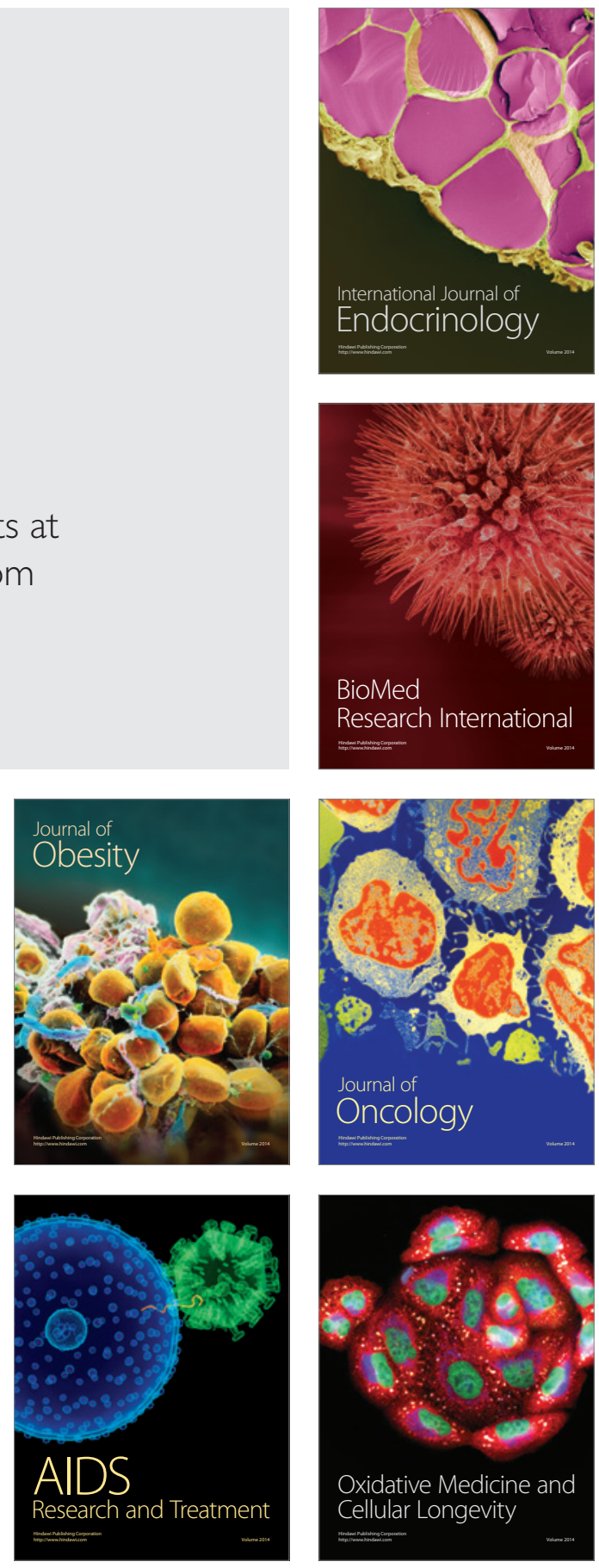